\title{
DETECTION OF CRACK FORMATION FOLLOWING CORONAL FLARING WITH THREE DIFFERENT INSTRUMENTS USING TWO EVALUATION METHODS (IN VITRO STUDY)
}

\author{
Sally M. Nazir ${ }^{l} B D S$, Amr M. Abdallah ${ }^{2} P h D$, Nayera A. Mokhless ${ }^{3} P h D$
}

\begin{abstract}
INTRODUCTION: Coronal flaring is now considered as an essential preparatory step in root canal treatment sequence. OBJECTIVES: To detect crack formation after coronal flaring of root canals with Gates Glidden (GG) drills, ProTaper Universal (PT) SX, and Endoflare (Ef) flaring instruments using cone beam computed tomography (CBCT) and scanning electron microscope (SEM). MATERIALS AND METHODS: Thirty mesiobuccal canals of mandibular first molars were selected.

Teeth specimens were classified into three equal groups according to the instrument used for coronal flaring. Group1: Gates Glidden drills, group 2: ProTaper Universal SX and group 3: Endoflare instruments. Preoperative and postoperative (CBCT) imaging was performed and defect formation was detected. All roots were sectioned horizontally at 2,4and $6 \mathrm{~mm}$ from the cementoenamel junction. The sections were inspected under SEM, and any defect formations were recorded and compared with CBCT images according to scoring system. Data were collected and then statistically analyzed at an alpha error of 0.05 . $\mathrm{P} \leq 0.05$ were considered significant.

RESULTS: The Ef file produced significantly less dentinal defects compared with the GG and PT SX at the three studied sections. Significant differences were found between the 3 groups at 2 and $4 \mathrm{~mm}$ with values $(\mathrm{P}=0.026) \&(\mathrm{P}=0.050)$ respectively, while no significant difference was found at $6 \mathrm{~mm}$ with value of $(\mathrm{P}=0.217)$ when using the 2 evaluation methods. There was a significant difference $(\mathrm{P}=0.049)$ between the two used evaluation methods.

CONCLUSIONS: Although all used coronal flaring instruments caused dentinal defects, Endoflare file showed the least defects. CBCT was not able to detect the smallest defects such as craze lines while SEM showed more capabilities and was considered as a confirmatory method. KEYWORDS: Coronal flaring, cracks, cone beam computed tomography, scanning electron microscope
\end{abstract}

$1-\quad$ B.D. S 2009

2- Professor of Endodontics, Faculty of Dentistry, Alexandria University

3- Assistant Professor of Endodontics, Faculty of Dentistry, Alexandria University

\section{INTRODUCTION}

The presence of cervical interferences leads to the formation of great tension on the file at the apical third which might be a cause of iatrogenic mishaps such as ledge formation, canal transportation and zipping. These complications can be avoided through coronal flaring which act as a principle preparatory step to allow more accurate working length and apical diameter determination, together with a better application and more effective action of irrigants, medicaments and filling materials. Manual and mechanical instrumentation techniques can be used to provide quick and efficient means of coronal root flaring. Although Mechanical (i.e. rotary flaring) reduces treatment time, yet the risk of complications as momentary stress concentration in the dentin would be expected, with the possibility of dentinal defects increasing after such a procedure.

Many coronal flaring instruments are now available in the market with different designs and materials, one of the most commonly and early used stainless steel coronal flaring instruments were the GG drills (Mani Inc, Tachigiken, Japan). However new nickel titanium instruments are also available for this use such as Protaper universal SX file (Dentsply Maillefer, Ballaigues, Switzerland) and Endoflare file (Micro-Mega, Besancon, France) having the advantage of super elasticity and less chances of strip perforation and canal transportation over conventional stainless steel GG drills (1).
Evaluation of dentinal defects can be done by using several diagnostic methods, either requiring horizontal root sectioning like microscopic evaluation or without like radiographs. Recently cone beam computed tomography is also used which can give a three-dimensional image of the root canal, adding the advantage of conforming a nondestructive technique capable of comparing root before and after instrumentation. To the best of our knowledge, there are few data in the literature related solely to the effect of coronal flaring instruments on crack formation. Therefore, the aim of the present study was to evaluate crack formation after flaring root canals with Gates Glidden drills, ProTaper Universal (SX instrument) and Endoflare instruments. The null hypothesis is that there would be differences in crack formation between the two evaluation methods used among the three used file groups.

\section{MATERIALS AND METHODS}

Thirty mesiobuccal canals of freshly extracted human permanent lower molars of almost same lengths and moderate curvature $\left(10-25^{\circ}\right)$ according to Schneider's technique (2) were selected, teeth were thoroughly cleaned after extraction by a brush and rinsed with tap water to remove any tissue remnants, debris and blood on its surface, disinfected and stored in saline until used. Teeth were visually inspected using a magnifying lens, any tooth with visible cracks were excluded and replaced. 


\section{Preparation of teeth}

Conventional access openings were prepared in all teeth using high speed large \#4 round (Komet Dental, Lemgo, Germany) and Endo-Z burs (Dentsply Maillefer, Ballaigues, Switzerland) under a water cooling system. The distal roots were removed and the Cusps were flattened using a tapered fissure bur to provide a uniform reference point coronally and to standardize working length of $15 \mathrm{~mm}$ till coronal two thirds.

The apical patency and working length (WL) of each canal were determined and recorded by passing \# $10 \mathrm{~K}$-file (MICRO-MEGA, Besancon, France) $1 \mathrm{~mm}$ beyond the apical foramen. Only teeth with initial binding file \# $10 \mathrm{k}$ file were included. The final WL was established $2 \mathrm{~mm}$ short of the recorded length. Before coronal flaring procedures, all root canals were prepared with \#10 and \#15 K-files to establish a glide path. Irrigation with $3 \mathrm{ml}$ of $2.5 \%$ sodium hypochlorite $\mathrm{NaOCl}$ using a 27 -gauge needle was done.

\section{Experimental Setup}

Each root was wrapped with a single layer of aluminum foil then embedded in acrylic resin and the aluminum foil was peeled off after setting of the resin. A hydrophilic vinyl polysiloxane impression material (Zhermack C-Silicones, Badia Polesine (Rovigo), Italy) replaced the space created by the foil to represent a simulated periodontal ligament, and the root was immediately repositioned (3).

\section{Pre-flaring Cone Beam Computed Tomography}

Evaluation of any radicular dentinal defects originally present were done for the full length of the root using Cone Beam Computed Tomography Scanner (GALILEOS Comfort PLUS Sirona the dental company, Germany) with high resolution isotropic voxel size $(0.25 / 0.125 \mathrm{~mm}$ voxel $)$, standard exposure time (14 seconds), Reconstruction time < $4 \mathrm{~min}$, tube voltage $85 \mathrm{KVp}$ and $5-7 \mathrm{~mA}$ and field of view $(15 \times 15 \times 15) \mathrm{cm}^{3}$ and $15,4 \mathrm{~cm}$ spherical imaging volume.

\section{Coronal flaring instrumentation}

\section{Grouping}

Teeth specimens were classified into three equal groups $(\mathrm{n}=10)$ according to the instrument used.

Group I: GG drills were used for coronal flaring with the rotational speed $(800 \mathrm{rpm})$ and the torque as suggested by the manufacturer. The sequence was in a crown down order with sizes of \#3, 2 \& 1 and WL of $11,13 \& 15$ respectively in a brushing motion. Each drill was used in an in and out motion in the canals without pressure until a resistance was met or reaching the WL.

Group II: PT SX files with an apical size of $0.19 \mathrm{~mm}$ were used for coronal flaring, with Endo-Mate AT motor NSK Nakanishi Inc., Kanuma, Tochigi, Japan) in continuous rotation motion at speed of $300 \mathrm{rpm}$ and $3 \mathrm{~N} / \mathrm{cm}$ torque. Files were used progressively down the canals till $15 \mathrm{~mm}$ in a brushing in and out motion without pressure an upward circumferential filing motion was performed to decrease and overcome cervical interferences.

Group III: Ef instrument (15 mm long, working length $10 \mathrm{~mm}$, and tip size of 25) were used for coronal flaring with Endo mate AT motor in continuous rotation motion at a constant and stable speed of $300 \mathrm{rpm}$ and $3 \mathrm{~N} / \mathrm{cm}$ torque. Files were used progressively down the canals till $15 \mathrm{~mm}$ in a gentle in and out motion without pressure an upward circumferential filing motion was performed to decrease and overcome cervical interferences.

In the three groups EDTA gel (Glyde File Prep, DENTSPLY, Ballaigues, Switzerland) was used to aid in root canal negotiation and lubrication. After 3 pecking motions the instrument was removed from the canal, cleaned with gauze and recapitulation using size \#10 K-File and irrigation with $3 \mathrm{ml} \mathrm{NaOCl} 2.5 \%$ using a 27-gauge needle was performed.

\section{Post-flaring Cone Beam Computed Tomography}

Post flaring CBCT scanning was done. A Comparison between the pre-and post-flaring CBCT images was performed and presence of new defects (craze lines, incomplete cracks, complete cracks) were detected and evaluated at 2, $4 \& 6 \mathrm{~mm}$ from cemento enamel junction. The teeth were kept moist in distilled water throughout all experimental procedures.

Dentinal defects were classified as follows according to Barreto et al. (4)

A. No defect: Root dentin without any lines or cracks on the external or the internal surface of the root

B. Incomplete crack: A line extending from the canal wall into the dentin without reaching the outer surface.

C. Complete crack: A line extending from the root canal wall to the outer surface of the root

D. Craze lines: All other lines that did not reach any surface of root or extend from the outer surface into the dentin but did not reach the canal wall.

\section{Scanning Electron Microscopic Prepartion $(5,6)$}

All specimens were removed from the acrylic blocks and sectioned horizontally at 2, 4, and $6 \mathrm{~mm}$ from the CEJ using low- speed double sided diamond disc (Kerr dental NTI Flex Diamond Disc) under water cooling and coded according to the groups and sections.

Dentinal defects (craze lines, incomplete cracks, complete cracks) at $2,4 \& 6 \mathrm{~mm}$ sections from CEJ in the coded specimens were observed and recorded using SEM (JEOL JSM-5300 Scanning Electron Microscope) operated between 15 and $20 \mathrm{Kev}$ with magnification of $(35,75,150$ $\mu \mathrm{m})$

\section{Dentinal defects evaluation}

The observed dentinal defects were evaluated according to the same scoring system. Comparison between the images recorded by the two evaluation methods was done.

\section{STATISTICAL ANALYSIS}

The differences in crack formation among the 3 groups were analyzed with the chi-square test for comparison between different groups regarding categorical variables, and if it was not valid it was substituted by Monte Carlo exact probability, Z-test for independent proportions. Testing was performed at the $95 \%$ confidence level $(\mathrm{P}=.05)$. All statistical analyses were performed using IBM SPSS Statistics 20 software (IBM SPSS Inc, Chicago, IL).

\section{RESULTS}

The number of root specimens with dentinal defects for all groups detected with both evaluation methods are shown in Figure1.

On comparing between the two used evaluation methods when the total number of each type of defect was calculated a significant difference was found $(\mathrm{P}=0.049)$. Table (1), Figures (2,3\&4).

When comparing between the results in the two evaluation methods obtained at each section $(2,4$ and $6 \mathrm{~mm})$ it was found that there was a significant difference between the three studied groups in dentinal defects formation at 2 and 4 
$\mathrm{mm} \quad(\mathrm{P}=0.026)$ and $(\mathrm{P}=0.050)$ respectively, while no significant difference was found at $6 \mathrm{~mm}(\mathrm{P}=0.217)$. Table (2)

When studying, the dentinal defects formed using the three studied coronal flaring instruments regardless the evaluation method used it was found that group III (Endoflare file) showed the least number of defects with a percentage of $66.7 \%$ followed by group II and group I with values of $44.4 \%$ and $27.8 \%$ respectively with a significant difference $(\mathrm{P}=0.012)$. Table (3)

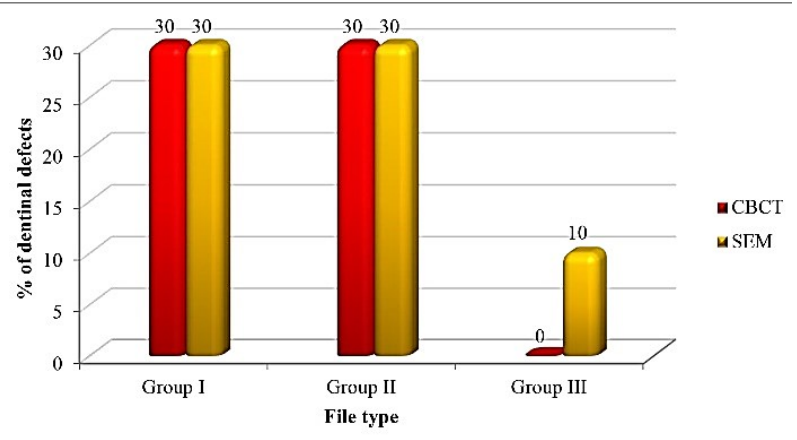

Figure (1): Represents the percentage of defects in the three studied groups

Table (1): Showing comparison between the two evaluation methods in defect observation

\begin{tabular}{|c|c|c|c|c|c|}
\hline \multirow{2}{*}{ Crack } & \multicolumn{4}{|c|}{ Method } & \multirow{2}{*}{ MCP } \\
\cline { 2 - 5 } & \multicolumn{2}{|c|}{ CBCT } & \multicolumn{2}{c|}{ SEM } & \\
\cline { 2 - 5 } & No & $\%$ & No & \% & \\
\hline No & 10 & $47.6 \%$ & 7 & $33.3 \%$ & $0.049 *$ \\
\hline Craze lines & 0 & $0.0 \%$ & 2 & $9.5 \%$ & \\
\hline $\begin{array}{c}\text { Incomplete } \\
\text { Incomplete + Craze } \\
\text { lines }\end{array}$ & 0 & $0.0 \%$ & 6 & $28.5 \%$ & \\
\hline $\begin{array}{c}\text { Complete + Craze } \\
\text { lines }\end{array}$ & 0 & $0.0 \%$ & 1 & $4.8 \%$ & \\
\hline $\begin{array}{c}\text { Complete } \\
+ \text { incomplete+ craze } \\
\text { line }\end{array}$ & 0 & $0.0 \%$ & 1 & $4.8 \%$ & \\
\hline
\end{tabular}

MCP: Mont Carlo exact probability

$* \mathrm{P}<0.05$ (significant)

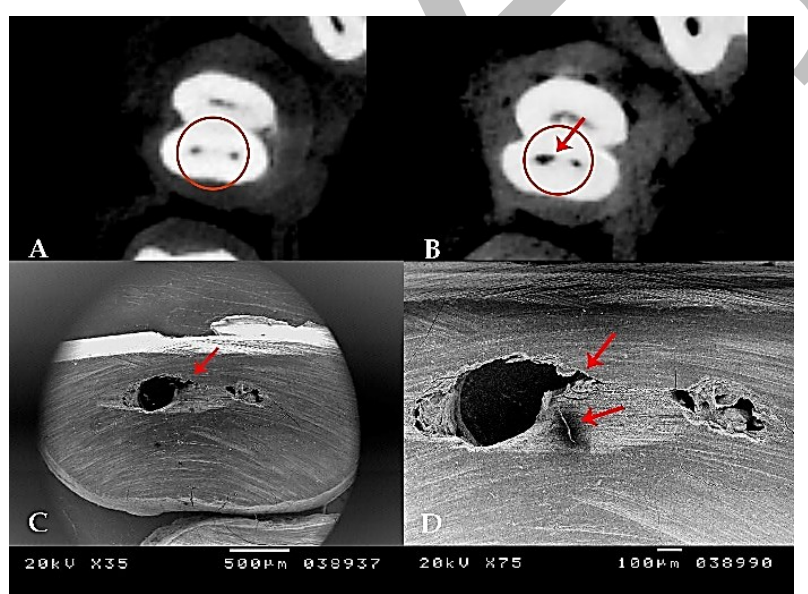

Figure (2): showing A: group I axial cross section preinstrumentation $\mathrm{CBCT}$ at $2 \mathrm{~mm}$ showing no dentinal defects, B: group I axial cross section post instrumentation CBCT at $2 \mathrm{~mm}$ showing incomplete crack, C: group I SEM at $\times 35$ magnification showing incomplete crack at $2 \mathrm{~mm}$, D: group I SEM at $\times 75$ magnification showing incomplete crack and craze lines at $2 \mathrm{~mm}$.

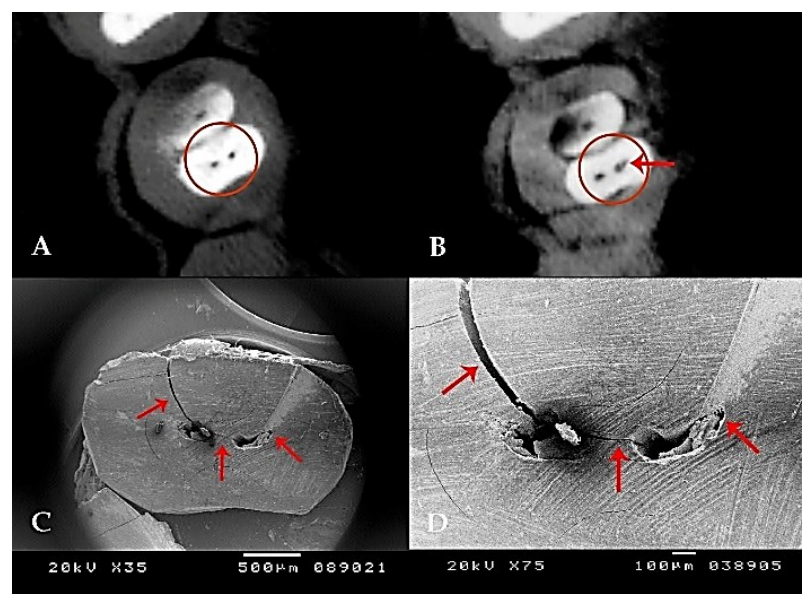

Figure (3): showing A: group II axial cross section preinstrumentation $\mathrm{CBCT}$ at $6 \mathrm{~mm}$ showing no dentinal defects, B: group II axial cross section post instrumentation CBCT at $6 \mathrm{~mm}$ showing incomplete crack, C: group II SEM at $\times 35$ magnification at $6 \mathrm{~mm}$ showing incomplete crack, craze lines and complete crack, D: group II SEM at $\times 75$ magnification at $6 \mathrm{~mm}$ showing incomplete crack, craze lines and complete crack.

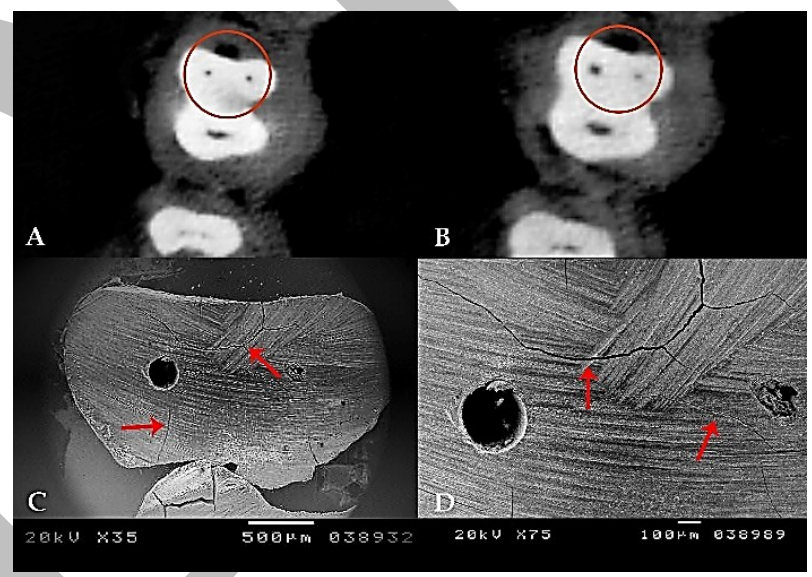

Figure (4): showing A: group III axial cross section preinstrumentation $\mathrm{CBCT}$ at $4 \mathrm{~mm}$ showing no defects, B: group III axial cross section post instrumentation $\mathrm{CBCT}$ at $4 \mathrm{~mm}$ showing no defects, C: group III SEM at $\times 35$ magnification at $4 \mathrm{~mm}$ showing craze lines D: group III SEM at $\times 75$ magnification at $4 \mathrm{~mm}$ showing craze lines

\section{DISCUSSION}

Coronal flaring is now considered as a principal preparatory step in root canal treatment sequence. The present study evaluated dentinal defects formed after using three coronal flaring instruments by comparing two evaluation methods CBCT and SEM.

In this study, CBCT was selected as the first choice in detection of dentinal defects in our evaluation in an attempt to eliminate the need of root sectioning, and because of its superiority and sensitivity in diagnosis of vertical root fracture (VRF) when compared to conventional periapical radiograph $(7,8)$ it might be claimed to have the same accurate results obtained in the detection of dentinal defects and fracture lines.

Pre-and post-instrumentation scanning were performed using CBCT, pre-instrumentation images were recorded to detect any cracks or defects originally present in the specimens before coronal flaring. Moreover, pre-and postinstrumentation images were studied and presence of new defects were detected. This was similar to the methodology used by Hartmann et al (9) Sanfelice et al (10) and Souza et al (11). 
Table (2): Showing the number of dentinal defects formed in each of the studied sections in the three groups

\begin{tabular}{|c|c|c|c|c|c|c|c|c|c|c|c|c|c|c|}
\hline \multirow{3}{*}{ Site } & \multirow{3}{*}{ File } & \multicolumn{12}{|c|}{ Crack } & \multirow{3}{*}{ MCP } \\
\hline & & \multicolumn{2}{|c|}{ No } & \multicolumn{2}{|c|}{ Craze lines } & \multicolumn{2}{|c|}{ Incomplete } & \multicolumn{2}{|c|}{$\begin{array}{c}\text { Incomplete + } \\
\text { Craze lines }\end{array}$} & \multicolumn{2}{|c|}{$\begin{array}{l}\text { Complete + } \\
\text { Craze lines }\end{array}$} & \multicolumn{2}{|c|}{$\begin{array}{c}\text { Complete+incomplete } \\
\text { +craze lines }\end{array}$} & \\
\hline & & No & $\%$ & No & $\%$ & No & $\%$ & No & $\%$ & No & $\%$ & No & $\%$ & \\
\hline \multirow{3}{*}{$2 \mathrm{~mm}$} & Group I & 0 & $0.0 \%$ & 0 & $0.0 \%$ & 4 & $66.7 \%$ & 2 & $33.3 \%$ & 0 & $0.0 \%$ & 0 & $0.0 \%$ & \multirow{3}{*}{$0.026^{*}$} \\
\hline & Group II & 4 & $66.7 \%$ & 0 & $0.0 \%$ & 2 & $33.3 \%$ & 0 & $0.0 \%$ & 0 & $0.0 \%$ & 0 & $0.0 \%$ & \\
\hline & Group III & 1 & $50.0 \%$ & 1 & $50.0 \%$ & 0 & $0.0 \%$ & 0 & $0.0 \%$ & 0 & $0.0 \%$ & 0 & $0.0 \%$ & \\
\hline \multirow{3}{*}{$4 \mathrm{~mm}$} & Group I & 0 & $0.0 \%$ & 0 & $0.0 \%$ & 5 & $83.3 \%$ & 1 & $16.7 \%$ & 0 & $0.0 \%$ & 0 & $0.0 \%$ & \multirow{3}{*}{0.050 * } \\
\hline & Group II & 2 & $33.3 \%$ & 0 & $0.0 \%$ & 2 & $33.3 \%$ & 2 & $33.3 \%$ & 0 & $0.0 \%$ & 0 & $0.0 \%$ & \\
\hline & Group III & 1 & $50.0 \%$ & 1 & $50.0 \%$ & 0 & $0.0 \%$ & 0 & $0.0 \%$ & 0 & $0.0 \%$ & 0 & $0.0 \%$ & \\
\hline \multirow{3}{*}{$6 \mathrm{~mm}$} & Group I & 5 & $83.3 \%$ & 0 & $0.0 \%$ & 0 & $0.0 \%$ & 0 & $0.0 \%$ & 1 & $16.7 \%$ & 0 & $0.0 \%$ & \multirow{3}{*}{0.217} \\
\hline & Group II & 2 & $33.3 \%$ & 0 & $0.0 \%$ & 2 & $33.3 \%$ & 1 & $16.7 \%$ & 0 & $0.0 \%$ & 1 & $16.7 \%$ & \\
\hline & Group III & 2 & $100.0 \%$ & 0 & $0.0 \%$ & 0 & $0.0 \%$ & 0 & $0.0 \%$ & 0 & $0.0 \%$ & 0 & $0.0 \%$ & \\
\hline
\end{tabular}

MCP: Mont Carlo exact probability

$* \mathrm{P}<0.05$ (significant)

Table (3): Showing the number and percentage of dentinal defects in the three studied groups

\begin{tabular}{|c|c|c|c|c|c|c|c|c|c|c|c|c|c|}
\hline \multirow{3}{*}{ File } & \multicolumn{12}{|c|}{ Crack } & \multirow{3}{*}{ MCP } \\
\hline & \multicolumn{2}{|c|}{ No } & \multicolumn{2}{|c|}{ Craze lines } & \multicolumn{2}{|c|}{ Incomplete } & \multicolumn{2}{|c|}{$\begin{array}{c}\text { Incomplete + } \\
\text { Craze lines }\end{array}$} & \multicolumn{2}{|c|}{$\begin{array}{c}\text { Complete + Craze } \\
\text { lines }\end{array}$} & \multicolumn{2}{|c|}{$\begin{array}{c}\text { Complete+incomplete }+ \\
\text { craze line }\end{array}$} & \\
\hline & No & $\%$ & No & $\%$ & No & $\%$ & No & $\%$ & No & $\%$ & No & $\%$ & \\
\hline Group I & 5 & $27.8 \%$ & 0 & $0.0 \%$ & 9 & $50.0 \%$ & 3 & $16.7 \%$ & 1 & $5.6 \%$ & 0 & $0.0 \%$ & \\
\hline Group II & 8 & $44.4 \%$ & 0 & $0.0 \%$ & 6 & $33.3 \%$ & 3 & $16.7 \%$ & 0 & $0.0 \%$ & 1 & $5.6 \%$ & $0.012 *$ \\
\hline Group III & 4 & $66.7 \%$ & 2 & $33.3 \%$ & 0 & $0.0 \%$ & 0 & $0.0 \%$ & 0 & $0.0 \%$ & 0 & $0.0 \%$ & \\
\hline
\end{tabular}

Cone Beam Computed Tomography Scanner system with a high resolution of $(0.2 \mathrm{~mm} / 0.125 \mathrm{~mm}$ voxel $)$ was used in this study, respecting the as low as reasonably achievable principle (ALARA principle) that the best choice for diagnostic use with a shorter scanning time and reduced radiation exposure to the patient is $(0.2-0.3 \mathrm{~mm})$ resolution (12). This was in conjunction with Özer (13) who stated that the accuracy was higher and the decision was easier with $0.125-\mathrm{mm}$ and $0.2 \mathrm{~mm}$ voxels than 0.3 and $0.4 \mathrm{~mm}$ voxels, and Tanimoto et al. (14) who reported that choosing a small voxel size without changing the radiation dose increases the resolution.

A second method for detection of various defects have been also used for the confirmation and evaluation of the accuracy of CBCT. Specimens were horizontally sectioned at 2,4 and $6 \mathrm{~mm}$ from the cemento enamel junction and studied using SEM, this was similar to studies carried out by Ashwinkumar et al. (15) in identifying formation of dentinal defects.

In the present study, a statistical significant difference was found between CBCT and SEM when the total number of each type of defect was calculated regardless the type of instrument used. Craze lines were detected only in SEM images and not in CBCT images, this might be attributed to either the greater magnification power used $(\times 35$ and $\times 75$ $\mu \mathrm{m})$ in SEM, this was in agreement with Cicek et al. (16) who found that craze lines (micro cracks) were more obviously seen using high magnification power $(\times 40 \mu \mathrm{m})$ and Özer $(17)$ who found that CBCT scans showed failure in reading of cracks and fracture lines of smaller widths less than $0.2 \mathrm{~mm}$. Or may be due to the root sectioning manipulations, this was in conjunction with Bier et al. (18) and Shemesh et al (19) who found that the sawing action could also result in dentinal micro cracks. On the other hand, most of the incomplete cracks were obviously detected in the two evaluation methods with minimal differences between them this might be attributed to the high $\mathrm{mA}$ value used in our study, where a reduction in $\mathrm{mA}$ may cause increased image noise, which eventually may adversely affect the diagnosis as stated by Neves et al. (20). In contrast to our findings Gunduz et al. (21) stated that the assessment of incomplete root fractures is a difficult diagnostic task. Complete cracks were detected in SEM images only but were not seen in CBCT images, this observation came in agreement with kajan et al. (22) who stated that even in CBCT examinations of teeth with clinical signs of root fracture, the fracture lines may not be visualized. 
The defects present in SEM images might be due to several reasons; the SEM preparatory procedures may help inducing artefacts and drying may cause soft tissue collapse and hard tissue cracks this was in agreement with Heard et al. (23). The communication of craze lines with incomplete cracks that reached the external wall forming complete cracks, or could also be due to communicating fracture lines in adjacent sections during the sectioning procedures this was in agreement with Onnink et al. (24). And were supported by optical coherence tomography stated by Shemesh et al. (25). Moreover, the low performance of CBCT (Galileos 3D) might be due to the presence of the image intensifier tube/charged coupled device instead of a flat-panel detector as reported by Katsumata et al. (26). However, in this study there were no defects seen related to the mesiolingual uninstrumented canal in the same studied section in comparison with the instrumented mesiobuccal canal, this observation verified that defects occurred during the coronal flaring instrumentation and not due to sectioning and preparatory SEM procedures.

In the current study, we compared between three coronal flaring instruments of different materials and designs (Gates Gliddden drills; St St, Protaper Universal SX, Endoflare files; NiTi) and evaluated dentinal defects formed. The Endoflare file group showed the least number of defects compared to the other groups, this result might be due to several possible factors as stated by Arslan et al. (27), such as the large number of instruments used in the Gates Glidden drill procedure which may result in more dentinal defects formation in comparison with Protaper SX and Endoflare file, the different rotational speeds of the instruments, the different instrument designs as Blum et al. (28) found that the design of the cutting blades could increase friction and stresses within the root canal and Kim et al. (29) who found a potential relationship between the design of NiTi instruments and the incidence of vertical root fractures. And the material of the instrument used where in our study Gates Glidden showed more cracks at $2 \mathrm{~mm}$ from CEJ which is the area of the most cervical interference, this came in conjunction with Porto Carvalho et al. (30) who explained the difference between stainless steel and NiTi instruments, and stated that NiTi instruments tend to stay better centered in the canal compared with stainless steel files and engine-driven GG drills.

In the present study Gates Glidden drills were preferred to be used in a crown down order, till reaching two third the working length (size \#3, \#2, \#1 and diameter of $0.9 \mathrm{~mm}, 0.7$ $\mathrm{mm}$, and, $0.5 \mathrm{~mm}$ respectively), as it was proved to be safer than serial sequence with less probability of perforation or thinning of root dentin which might affect dentinal defects formation as stated by Filho et al. (31) and Wu et al. (32) who reported that using GG drills in mandibular molars weakens the furcation area regardless the size of the instrument used or the penetration depth. In this study Both post CBCT and SEM images of GG group showed incomplete crack formation at 2 and $4 \mathrm{~mm}$ in addition to craze lines formation at the same levels and complete crack formation at $6 \mathrm{~mm}$ in SEM images only, this was in agreement with Wilcox et al. (33) who stated that the amount of dentine removed during root canal preparation was associated with craze lines.

In the current study Protaper universal SX files were used with a variable taper ranging from $3.5 \%-19 \%$ and have a greater taper of $19 \%$ between D6 and D9. The taper of the instrument and that of the preparation could be a contributing factor in the generation of dentinal defects as stated by Rundquist \& Versluis (34) and Souza bier et al. (35). In this study both post CBCT and SEM images showed incomplete cracks at 4 and $6 \mathrm{~mm}$ while no defects were found at $2 \mathrm{~mm}$ in addition to craze line formation at 4 and $6 \mathrm{~mm}$ and complete crack formation at $6 \mathrm{~mm}$ in only one tooth observed in SEM images. This observation was supported by Sathorn et al. (36) who concluded that by maintaining the canal size as small as practical, a reduction in fracture susceptibility could be expected.

Endoflare files were used in this study with a constant taper of $12 \%$ and the least dimensions of $0.61 \mathrm{~mm}$ engaged in the canals compared with GG drills and PT SX, showed the least number of defects in both post instrumentation CBCT and SEM images with no cracks (incomplete, complete )were seen at all sections from CEJ, only craze lines were detected in SEM images at 2 and $4 \mathrm{~mm}$, because the greater the taper dimensions of the instrument at the depth of the canals the more it affects the crack formation, this might explain the superior results obtained by Ef file group, this was in agreement with Arslan et al. (27) and Yoldas et al . (37) who stated that the extent of defect formation was related to constant or progressive taper type, the tip design, cross-section geometry, constant or variable pitch, and flute form of the instruments.

It was found that the three instruments could be beneficial for coronal flaring in terms of crack formation, the null hypothesis was not rejected because a significant difference in crack formation were obtained between the three flaring instruments as evaluated by SEM while it was rejected based on CBCT evaluation as no significant difference was found between the three coronal flaring instruments groups.

\section{CONCLUSIONS}

Within the limitations of this study, it was concluded that: All the in -vitro tested coronal flaring instruments produced dentinal defects, irrespective of their design or material. Scanning electron microscope allowed the inspection of craze lines and smaller defects better than cone beam computed tomography. It can be used as a confirmatory tool to Cone beam computed tomography in dentinal defects evaluation.

\section{CONFLICT OF INTEREST}

The authors declare that they have no conflicts of interest.

\section{REFRENCES}

1. Peters OA, Peters CI, Schonenberger K, Barbakow F. Pro Taper rotary root canal preparation: effect of canal anatomy on final shape analyzed by micro CT. Int Endod J 2003; 36:86-92.

2. Schneider SW. Comparison of the canal preparation in straight and curved root canals. Oral Surg Oral Med Oral Pathol. 1971; 32:271-5

3. Liu R, Kaiwar A, Shemesh H. Incidence of Apical Root Cracks and Apical Dentinal Detachments after Canal Preparation with Hand and Rotary Files at Different Instrumentation Lengths. J Endod. 2013; 39:129-32

4. Barreto MS, MoraesRdo A, Rosa RA, Moreira CH, So MV, Bier CA. Vertical root fractures and dentin defects: Effects of root canal preparation, filling and mechanical cycling. J Endod. 2012; 38:1135-9. 
5. Tahmasebi P, Javadpour F, Sahimi M. Three-Dimensional Stochastic Characterization of Shale SEM Images. Transp Porous Med. 2015; 3:521-31.

6. Canillioglu E, Bahcesehir ES. Preparation Techniques of Luminal and Hard Tissues for Scanning Electron Microscopy. In: Méndez-Vilas A, ed. Microscopy: advances in scientific research and education. Spain: Formatex Research Center; 2014;741-6.

7. Bernardes RA, deMoraes IG, Duarte MAH, Azevedo BC, de Azevedo JR, Bramante CM. Use of cone-beam volumetric tomography in diagnosis of root fractures. Oral Surg Oral Med Oral Pathol Oral Radiol Endod. 2009; 108:270-7.

8. Hassan B, Metska ME, Ozok AR, Van der Stelt P, Wesselink PR. Detection of vertical root fractures in endodontically treated teeth by a cone beam computed tomography scan. J Endod. 2009; 35:719-22.

9. Hartmann MSM, Barletta FB, Fontanella VRC, Vanni JR. Canal transportation after root canal instrumentation: a comparative study with computed tomography. J Endod. 2007; 33:962-5.

10. Sanfelice CM, da Costa FB, Reis Só MV, Vier-Pelisser F, Souza Bier CA, Grecca FS. Effects of Four Instruments on Coronal Pre-enlargement by Using Cone Beam Computed Tomography. J Endod. 2010; 36:858-61.

11. Sousa K, Andrande-junior CV, Da silva JM, De-Deus G. Comparison of the effects of TripleGates and GatesGlidden burs on cervical dentin thickness and root canal area by using cone beam computed tomography J Appl Oral Sci. 2015;23:164-8

12. Farman AG. ALARA still applies. Oral Surg Oral Med Oral Pathol Oral Radiol Endod.2005;4:395-7.

13. Özer SY. Detection of Vertical Root Fractures by Using Cone Beam Computed Tomography with Variable Voxel Sizes in an in Vitro Model. J Endod. 2011; 37:75-9.

14. Tanimoto H, Arai Y. The effect of voxel size on image reconstruction in cone-beam computed tomography. Oral Radiol. 2009; 25:149-53.

15. Ashwinkumar V, Krithikadatta J, Surendran S, Velmurugan $\mathrm{N}$. Effect of reciprocating file motion on microcrack formation in root canals: an SEM study. Int Endod J. 2014; 47:622-7.

16. Çiçek E, KoçAK MM, SağLam BC, KoçAK S. Evaluation of Microcrack Formation in Root Canals After Instrumentation with different NiTi Rotary File Systems: A Scanning Electron Microscopy Study. Scanning. 2015; 37:49-53.

17. Özer SY. Detection of Vertical Root Fractures of Different Thicknesses in Endodontically Enlarged Teeth by Cone Beam Computed Tomography versus Digital Radiography. J Endod. 2010; 36:1245-9.

18. Bier CA, Shemesh H, Tanomaru-Filho M, Wesselink PR, $\mathrm{Wu}$ MK. The ability of different nickel-titanium rotary instruments to induce dentinal damage during canal preparation. J Endod. 2009; 35:236-8.

19. Shemesh H, Bier CA, Wu MK, Tanomaru-Filho M, Wesselink PR. The effects of canal preparation and filling on the incidence of dentinal defects. Int Endod J. 2009; 42:208-13.

20. Neves FS, Souza TC, de-Azevedo-Vaz SL. Influence of cone-beam computed tomography milliamperage settings on image quality of the mandibular third molar region. Oral Radiol. 2014; 30:27-31.

21. Gunduz K, Avsever H, Orhan K. Comparison of intraoral radiography and cone beam computed tomography for the detection of vertical root fractures: an in vitro study. Oral Radiol 2013; 29:6-12.

22. Kajan ZD, Taromsari M. Value of cone beam CT in detection of dental root fractures. Dentomaxillofac Radiol. 2012; 41:3-10.

23. Heard F, Walton RE. Scanning electron microscope study comparing four root canal preparation techniques in small curved canals. Int Endod J. 1997; 30:323-31.

24. Onnink PA, Davis RD, Wayman BE. An in vitro Comparison of incomplete root fractures associated with three obturation techniques. J Endod. 1994;20;32-7.

25. Shemesh H, Van Soest G, Wu MK, Wesselink PR. Diagnosis of vertical root fracture with optical coherence tomography. J Endod. 2008; 34:739-42

26. Katsumata A, Hirukawa A, Okumura S, Naitoh M, Fujishita M, Ariji E, et al. Relationship between density variability and imaging volume size in cone-beam computerized tomographic scanning of the maxillofacial region: an in vitro study. Oral Surg Oral Med Oral Pathol Oral Radiol Endod. 2009; 107:420-5.

27. Arslan H, Karataş E, Capar ID, Ozsu D, Doğanay E. Effect of ProTaper Universal, Endoflare, Revo-S, HyFlex Coronal Flaring Instruments, and Gates Glidden Drills on Crack Formation. J Endod. 2014; 40:1681-3.

28. Blum JY, Machtou P, Ruddle C, Micallef JP. Analysis of mechanical preparations in extracted teeth using ProTaper rotary instruments: value of the safety quotient. J Endod. 2003; 29:567-75.

29. Kim HC, Lee MH, Yum J, Versluis A, Lee CJ, Kim BM. Potential relationship between design of nickel-titanium rotary instruments and vertical root fracture. J Endod. 2010; 36:1195-9.

30. Porto Carvalho LA, Bonetti I, Gagliardi Borges MA. A comparison of molar root canal preparation using stainless steel and nickel-titanium instruments. J Endod.1999; 25:807-10.

31. Coutinho-Filho T, De-Deus G, Gurgel-Filho ED, RochaLima AC, Dias KR, Barbosa CA. Evaluation of the risk of a stripping perforation with Gates-Glidden drills: serial versus crown-down sequences. Braz Oral Res. 2008; 22:1824.

32. Wu MK, Van der Sluis LW, Wesselink PR. The risk of furcal perforation in mandibular molars using GatesGlidden drills with anticurvature pressure. Oral Surg Oral Med Oral Pathol Oral Radiol Endod. 2005; 99:378-82.

33. Wilcox LR, Roskelley C, Sutton T. The relationship of root canal enlargement to finger-spreader induced vertical root fracture. J Endod. 1997; 23:533-4.

34. Rundquist BD, Versluis A. How does canal taper affect root stresses. Int Endod J. 2006; 39:226-37.

35. Sousa BC, Costa-Filho JR, Almeida-Gomes F, ManígliaFerreira C, Gurgel-Filho ED, Albuquerque DS. Evaluation of the dentin remaining after flaring using gates glidden drills and protaper rotary files. RSBO. 2011; 8:194-9.

36. Sathorn C, Palamara JE, Messer HH. A comparison of the effects of two canal preparation techniques on root fracture susceptibility and fracture pattern. J Endod. 2005; 31:283-7.

37. Yoldas O, Yilmaz S, Atakan G, Kuden C, Kasan Z. Dentinal Microcrack Formation during Root Canal Preparations by Different NiTi Rotary Instruments and the Self-Adjusting File. J Endod. 2012; 38:232-5. 